\title{
"HECHA LA LEY, HECHA LA TRAMPA": AVANCES Y DESAFÍOS EN TORNO A LA NORMATIVA SOBRE EXPLOTACIÓN SEXUAL COMERCIAL EN COSTA RICA
}

\section{"EVERY LAW HAS A LOOPHOLE": ADVANCES AND CHALLENGES ON THE REGULATIONS ON COMMERCIAL SEXUAL EXPLOITATION IN COSTA RICA}

\author{
Andrés Castillo Vargas*
}

\section{RESUMEN}

El presente artículo efectúa un recorrido por la normativa nacional e internacional vinculada al tema de explotación sexual comercial, con el objetivo de reflexionar en torno a su aplicabilidad para finalmente esbozar algunas recomendaciones que busquen mejorar la respuesta del Estado costarricense y de sus instituciones en el abordaje de esta problemática. Los hallazgos encontrados sugieren que a pesar de la existencia de leyes que protegen a las víctimas y sancionan a quienes les explotan sexualmente, el Estado costarricense aún no ha desarrollado mecanismos eficaces para trabajar con el potencial contenedor de las familias de las víctimas, crear políticas culturales de cero tolerancia y fortalecer la respuesta ante el problema en el ámbito local o comunitario.

PALABRAS CLAVE: EXPLOTACIÓN SEXUAL COMERCIAL * NORMATIVA NACIONAL * NORMATIVA INTERNACIONAL * POLÍTICAS PÚBLICAS * DERECHOS HUMANOS

\section{ABSTRACT}

This article takes a look at the national and international regulations related to the issue of Commercial Sexual Exploitation, in order to reflect on their applicability and to outline some recommendations that seek to improve the response of the Costa Rican government and its institutions in addressing this problem. The findings suggest that despite the existing laws to protect victims and punish sexual exploiters, the Costa Rican government has not yet developed effective mechanisms for working with potential holding capacities of the victim's families, for creating cultural policies zero tolerance and for strengthening the problem response in the local or community level.

KEYWORDS: COMMERCIAL SEXUAL EXPLOITATION * NATIONAL NORMATIVE * INTERNATIONAL NORMATIVE * PUBLIC POLICY * HUMAN RIGHTS

Escuela de Psicología y en el Instituto de Investigaciones Psicológicas de la Universidad de Costa Rica, Costa Rica. andres.castillo@ucr.ac.cr 


\section{INTRODUCCIÓN}

En los últimos años, los países de América Latina y el Caribe se han comprometido a prevenir y eliminar la explotación sexual comercial de personas menores de edad (ESC), mediante la firma de declaraciones políticas $y$ la ratificación de distintas convenciones internacionales. La aprobación y la ratificación de estos instrumentos han comprometido públicamente a los Estados a implementar todas las acciones necesarias para hacer efectivos, dentro de su territorio, los compromisos adscritos en dichos convenios internacionales; principalmente, desarrollando acciones en los ejes de prevención, atención y sanción de este delito, los cuales deben verse reflejados en políticas públicas que impacten directamente sobre esta problemática y contribuyan a su eliminación progresiva.

De esta manera, cuando un Estado ratifica un convenio internacional, este adquiere el estatus de Estado Parte de dicho convenio, lo cual significa que se ha comprometido de forma pública con la comunidad internacional a realizar todas las modificaciones necesarias dentro de su legislación interna para armonizar $y$ adecuar sus leyes a los compromisos internacionales adquiridos. Este sentido de obligatoriedad es lo que se denomina "carácter vinculante" (Bruna, 2003).

Sin embargo, las lecciones aprendidas acerca de la dinámica que caracteriza al comercio sexual con personas menores de edad, han vislumbrado la imperiosa necesidad no solo de crear nuevas leyes que tipifiquen este tipo de delito, sino también de conjugar esfuerzos y crear mecanismos de exigibilidad de derechos, en donde las instituciones estatales coordinen entre sí y funcionen como centinelas del cumplimiento y ejercicio de las garantías fundamentales que poseen las niñas, los niños $y$ adolescentes (NNA); ya que la permanencia en el comercio sexual de muchas personas menores de edad es sinónimo de la ineficiencia de las instituciones públicas por brindarles protección y seguridad.

Por esta razón, se considera que la ESC es una expresión extrema de la violencia social y familiar, debido a que existe una respuesta institucional deficiente que convierte a las familias de estos niños, niñas y adolescentes en el primer ámbito de violación de derechos; por cuanto es dentro de la familia donde inicialmente se presentan los primeros factores de riesgo que vulnerabilizan a las personas menores de edad frente al "lucrativo" negocio del sexo (Claramunt, 2008).

Estos dos niveles de desprotección, estatal $y$ familiar, junto al reforzamiento social que existe respecto a la objetivización del cuerpo femenino y la tolerancia comunitaria ante este fenómeno (Salas y Campos, 2004), hacen factible que quienes explotan sexualmente despojen a sus víctimas de su condición humana y las cataloguen como objetos sexuales de intercambio comercial. Al tomar en consideración este panorama, se vuelve necesaria la reflexión en torno a la aplicabilidad de la normativa nacional e internacional en la ejecución de políticas $y$ estrategias dirigidas a disminuir la vulnerabilidad social que experimentan las personas menores de edad frente a las redes de delincuencia sexual organizada.

Dicha vulnerabilidad debe entenderse como todas aquellas características individuales, familiares y comunitarias que exponen a las personas menores de 18 años a una posición de mayor riesgo frente a la explotación sexual. La misma comprende aspectos individuales, políticos, culturales y económicos que se construyen $y$ reconstruyen socialmente, de allí la importancia de modificarlos e impactar sobre ellos, mediante la creación de factores de protección a nivel estatal, familiar y comunitario que disminuyan al máximo el riesgo de que niños, niñas y adolescentes puedan convertirse en futuras víctimas de este delito (Programa Internacional para la Erradicación del Trabajo Infantil y Organización Internacional del Trabajo [IPEC/OIT], 2004a).

Por estas razones, la implementación eficaz de normas específicas para esta problemática puede contribuir considerablemente a que las personas menores de edad disfruten plenamente de su derecho a vivir libres de todo tipo de maltrato o explotación. De este modo, las políticas públicas constituyen uno de los elementos clave que poseen los Estados para combatir tal forma de esclavitud moderna, 
al definir principios, objetivos, prioridades, derechos y responsabilidades legales respecto al accionar de sus instituciones.

Partiendo de las anteriores reflexiones, en el marco del presente artículo se realizará un recorrido por la normativa internacional $y$ nacional vinculada a la ESc, con el objetivo de identificar los avances y los desafíos en torno a su aplicabilidad e implementación para finalmente esbozar algunas recomendaciones que busquen mejorar la respuesta del Estado costarricense $y$ de sus instituciones en el abordaje de esta problemática.

\section{NORMAS Y REUNIONES INTERNACIONALES VINCULADAS AL TEMA DE EXPLOTACIÓN SEXUAL COMERCIAL}

Con la finalidad de comprender la relación entre las políticas públicas nacionales y la normativa internacional vinculada al tema de explotación sexual comercial, es fundamental señalar que a partir de 1989 (año en el cual se crea la Convención de Derechos del Niño), la comunidad internacional ha promulgado una serie de convenciones $y$ declaraciones internacionales que buscan reconocer la ciudadanía social (Marshall y Bottomore, 1998) y los derechos humanos de todas las personas menores de edad, sin distinción de sexo, género, edad, etnia o situación social; algunas de estas convenciones o declaraciones son: el Convenio 182 de la Organización Internacional del Trabajo
(OIT) (OIT, 1999a), la Convención de las Naciones Unidas contra la Delincuencia Organizada (Asamblea General de las Naciones Unidas, 2000a); entre otras. Sumado a estos instrumentos internacionales, se han realizado reuniones regionales, subregionales, hemisféricas y mundiales, enfocadas en el abordaje que los "Estados Parte" deben realizar de esta transgresión a las garantías fundamentales que poseen los niños, las niñas y adolescentes.

Es así que, para comprender el posicionamiento adquirido por la ESC en la agenda nacional e internacional, no solo es necesario conocer la normativa (leyes) concerniente a esta, sino también todos aquellos espacios de reflexión en los cuales la comunidad internacional ha unido esfuerzos para la erradicación progresiva de este flagelo social.

No obstante, antes de conocer cuáles han sido las reuniones internacionales referentes a la prevención, atención, sanción y eliminación de la ESC y sus posteriores declaraciones políticas y jurídicas, es prudente efectuar un breve recorrido por la normativa internacional abocada a este tema. En este sentido, dada la complejidad de la explotación sexual comercial de personas menores de edad, el marco jurídico internacional que sirve de guía en el desarrollo de acciones encausadas a su eliminación, está compuesto principalmente por los instrumentos señalados enla figura 1 (IPEC/OIT, 2002, 2004a y 2004b). 
FIGURA 1

INSTRUMENTOS INTERNACIONALES EN MATERIA DE ESC
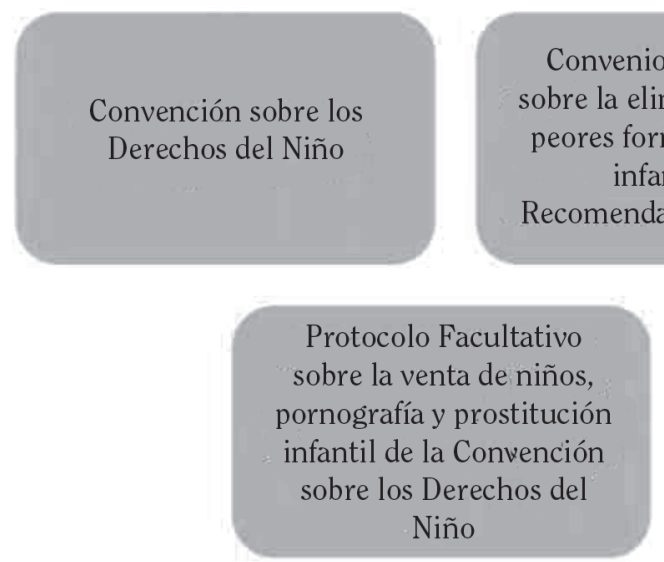

Protocolo Facultativo sobre la venta de niños, pornografía y prostitución infantil de la Convención sobre los Derechos de Niño
Convención Interamericana sobre tráfico internacional de menores

Fuente: Elaboración propia.

$\diamond \quad$ La Convención sobre los Derechos del Niño (Asamblea General de las Naciones Unidas, 1989): es "el principal instrumento internacional que recoge el consenso de los países que integran el Sistema de Naciones Unidas en materia de derechos humanos de las niñas, los niños y las personas adolescentes" (IPEC/ OIT, 2002, p. 43). Fue adoptada por la Organización de Naciones Unidas (ONU) en el año de 1989 y ratificada por Costa Rica en el año de 1990. Si bien no es una convención específica al tema de ESC, constituye el paradigma de acción universal para la comprensión, promoción y protección de los derechos humanos de las personas menores de edad $y$ el interés superior del niño; resaltando en los artículos 34, 35 y 36, el compromiso de los "Estados Parte" de proteger a las personas menores de edad de la explotación sexual comercial, el secuestro, la venta, la trata $y$ todo tipo de tratos crueles, inhumanos o degradantes.

$\diamond \quad$ El Convenio 182 de la OIT sobre la eliminación de las peores formas de trabajo infantil (oIT, 1999a) y su Recomendación nro. 190 (OIT, 1999b) buscan "obtener compromisos de los
Estados Parte dirigidos a tomar las medidas necesarias para erradicar en forma prioritaria las peores formas de trabajo infantil, incluidos el establecimiento y la aplicación de sanciones penales, o de otra índole, según proceda" (IPEC/ oIT, 2002, pp. 48-49). Dicho Convenio, ratificado por Costa Rica en el año 2001, conceptualiza en su artículo 3 a las peores formas de trabajo infantil como todas aquellas formas de esclavitud o prácticas análogas a la esclavitud, tales como la utilización, el reclutamiento o la oferta de niños, niñas y personas adolescentes para la prostitución, la producción de pornografía o actuaciones pornográficas, el uso de personas menores de edad para la realización de actividades ilícitas y todos aquellos trabajos que por su naturaleza dañen la salud, la seguridad o la moralidad de los niños y las niñas (IPEC/OIT, 2004e).

$\diamond \quad$ La Convención Interamericana sobre tráfico internacional de menores, adoptada por la Organización de Estados Americanos (OEA) en el año de 1994 y ratificada por Costa Rica en el año 2001 (OEA, 1994), tiene por objetivo principal la prevención y sanción del tráfico internacional de menores, así como, la regulación 
por parte de los "Estados Parte", de los aspectos civiles y penales concernientes al mismo. De este modo, tal y como se especifica en su artículo 1, cada Estado se compromete a instaurar un sistema de cooperación internacional que establezca las disposiciones legales $y$ administrativas que aseguren la pronta restitución de las personas menores de edad víctimas del tráfico internacional, teniendo en cuenta el interés superior del niño en todas las acciones propuestas e implementadas (IPEC/OIT, 2007).

El Protocolo Facultativo sobre la venta de niños, pornografía y prostitución infantil de la Convención sobre los Derechos del Niño (Asamblea General de las Naciones Unidas, 2000b). Fue ratificado por Costa Rica en el año 2002, y establece:

... que los Estados Parte adoptarán todas las medidas para que, como mínimo, los actos o actividades que se enumeran queden integralmente comprendidos en su legislación penal, tanto si se ha cometido dentro como fuera de sus fronteras, o si se han perpetrado individual $o$ colectivamente. Estos actos relacionados con la explotación sexual, y según el artículo 3, son: el ofrecimiento, entrega o aceptación, por cualquier medio, de un niño [niña o persona adolescente] con fines de explotación sexual, transferencia con fines de lucro de órganos del niño, trabajo forzoso del niño o niña; la oferta, posesión, adquisición o entrega de un niño [niña o persona adolescente] con fines de prostitución y la producción, distribución, divulgación, importación, exportación, oferta, venta o posesión de pornografía infantil (IPEC/ OIT, 2002, p. 49).

$\diamond \quad$ La Convención de Naciones Unidas contra la Delincuencia Organizada Transnacional (Asamblea General de las
Naciones Unidas, 2000a) y su Protocolo para prevenir, reprimir y sancionar la trata de personas (Protocolo de Palermo), ratificados por Costa Rica en el año 2003 (Asamblea General de las Naciones Unidas, 2000c), comprende a la Trata como el acto de:

...captar, transportar, trasladar y acoger o recibir a personas menores de 18 años recurriendo o no a la amenaza, el uso de la fuerza y otras formas de coacción, el rapto, el fraude, el engaño, el abuso de poder, la situación de vulnerabilidad, la concesión o recepción de pagos o beneficios para obtener el consentimiento de una persona que tenga autoridad sobre otra con fines de explotación sexual (artículo 3 inciso A de la Convención de las Naciones Unidas contra la Delincuencia Organizada Transnacional, 2000) (Monge y Cruz, 2004, p. 35).

Todos estos instrumentos internacionales mencionados con anterioridad, poseen en común ser un ejemplo claro de los procesos de tipificación, especificación y positivización de los derechos humanos de las personas menores de edad. Asimismo, buscan impactar en las diversas modalidades $y$ manifestaciones en que puede presentarse la ESC, por medio del establecimiento de mecanismos jurídicos y administrativos que aseguren la protección de las víctimas y la sanción de las personas explotadoras; sin embargo, dadas las características de este delito, también pueden considerarse otras normas o declaraciones del derecho internacional como normativas vinculadas al tema, al formar parte del núcleo central de los derechos humanos y constituirse en elementos progresivos e indispensables para la interpretación y la comprensión integral de la producción jurídica internacional.

En este ámbito, es importante reconocer que, si bien gran parte de la normativa internacional referente a los derechos humanos de las mujeres no reseña de forma explícita el tema de ESC, sí brinda aportes en materia de prevención 
y eliminación de este flagelo social, por cuanto resguarda las garantías fundamentales de las niñas y las adolescentes, quienes son las principales víctimas de este delito. Por ejemplo, la Convención Interamericana para Prevenir, Sancionar y Erradicar la Violencia contra la Mujer - Convención de Belém do Pará- (Organización de Estados Americanos, 1994) y la Convención para la Eliminación de todas las Formas de Discriminación contra la Mujer - CEDAW- (Organización de Naciones Unidas [onu], 18 de diciembre de 1979). Del mismo modo, es relevante subrayar el rol que cumple la Agenda 2030 y los Objetivos de Desarrollo Sostenible (ODS) por cuanto aluden a factores de vulnerabilidad que tienen relación directa con la problemática de ESC, además de aspirar a que todas las personas gocen de paz, bienestar y prosperidad (Naciones Unidas, 2018). Retomando esta idea, Monge y Cruz (2004) consideran que:

... a la par de la normativa penal, los Estados deben impulsar, aprobar y reformar otras leyes de naturaleza civil, de familia, de niñez y adolescencia, e incluso de naturaleza administrativa, dirigidas a reforzar los mecanismos de tutela de derechos de las personas menores de edad en otros ámbitos, impulsar legislación que prevenga la violencia sexual contra las personas menores de edad, $y$ que promuevan una educación no sexista $y$ una educación sexual integral en el marco de las políticas públicas de prevención y atención de la ESC (p.13).

Es así que las normas internacionales reconocen que la ESC es una forma de esclavitud moderna, una manifestación extrema de la violencia basada en género, una cadena sistemática de violaciones a los derechos humanos y una forma de explotación económica, e instan:

...a los Estados a tomar medidas para prevenir $y$ sancionar, incluso penalmente, este flagelo. Precisamente en este contexto, los países de la región, desde el año 1999 y principalmente desde el año 2003, han promovido discusiones técnicas, políticas y legislativas para reformar la legislación penal (procesal y sustantiva) $y$ adecuar la normativa interna a los contenidos mínimos que exigen los instrumentos internacionales en esta materia (IPEC/OIT, 2007, p. 5).

La ratificación de la normativa internacional vinculada al tema de Esc no solo ha aspirado a entrar en vigor, sino que también pretende que los Estados operacionalicen una serie de principios básicos que demuestren, con acciones concretas, la aplicación del enfoque de derechos humanos en la protección integral de las personas menores de edad. Algunos de estos principios básicos son (IPEC/OIT, 2004a):

1) Todas las personas menores de 18 años tienen el derecho a estar protegidas contra el comercio sexual.

2) Las personas menores de edad no pueden consentir un delito sobre ellas.

3) Los niños, niñas y adolescentes tienen derecho a la convivencia familiar y a la protección integral de todos sus derechos.

4) Si las familias y comunidades no logran proteger a las personas menores de edad contra la ESC, es responsabilidad estatal mediar y garantizar su protección.

5) Los Estados deben legislar para que las manifestaciones $y$ modalidades de la ESC sean contempladas como delitos graves en sus Códigos Penales. Además, deben crear leyes dentro de su normativa interna, acordes al enfoque de derechos y a la doctrina de protección integral, que resguarden las garantías fundamentales de las personas menores de edad y que reconozcan a todo NNA como personas garantes de derechos, sin importar su condición social, familiar o económica.

Por otra parte, adicional a estos principios y convenciones, la comunidad internacional ha desarrollado una serie de reuniones que han tenido como fin primordial, el impulso de acciones conjuntas en la implementación de políticas sociales y culturales que logren impactar en las causas que originan la Esc. Gracias al reconocimiento que la comunidad internacional 
otorgó a la ESC como una de las violaciones más severas a los derechos humanos de las personas menores de 18 años, es que en agosto de 1996 se realizó en Estocolmo (Suecia), el Primer Congreso Mundial contra la Explotación Sexual Comercial de Niños, Niñas y Adolescentes.

La importancia de este primer congreso radica en que los países participantes vislumbraron la necesidad de elaborar planes nacionales de acción específicos para la prevención y erradicación de la explotación sexual comercial de personas menores de edad. Para ello, materializaron sus acuerdos en la resultante "Declaración y Programa de Acción contra la Explotación Sexual Comercial” (IPEc/oIT, 2004a).

Dicho documento estableció 5 áreas prioritarias de trabajo que se han mantenido en los distintos compromisos internacionales sobre la temática, y que han orientado a los países en la erradicación de este problema (figura 2).

FIGURA 2

ÁREAS PRIORITARIAS PARA LA PREVENCIÓN Y ERRADICACIÓN DE LA EXPLOTACIÓN SEXUAL COMERCIAL DE PERSONAS MENORES DE EDAD

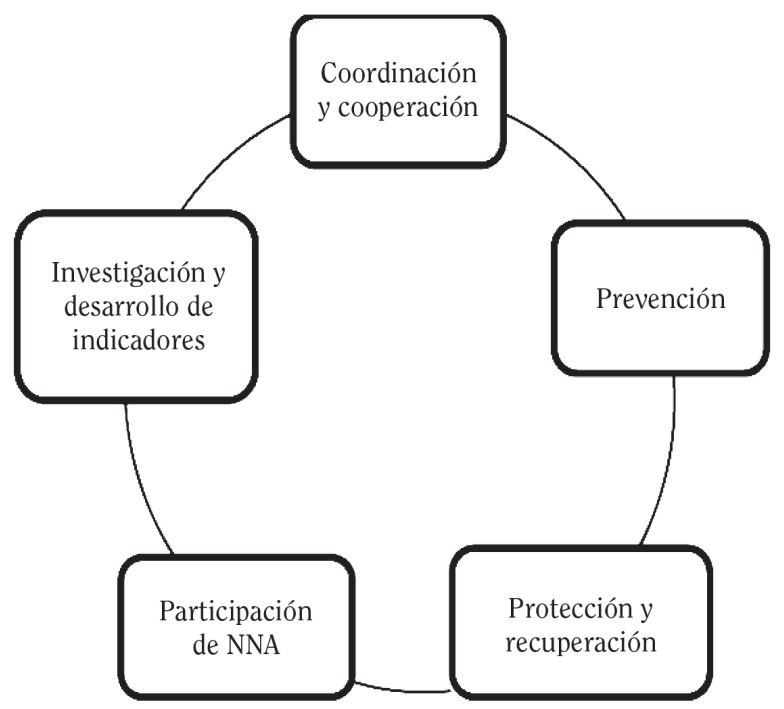

Fuente: Elaboración propia a partir de IPEc/OIT, 2004a.

Posterior a este primer congreso, en noviembre de 2001, se realiza en la ciudad de Montevideo (Uruguay), la Consulta Regional sobre Explotación Sexual Infantil con el propósito de evaluar los avances y retrocesos desde Estocolmo y establecer las bases de una estrategia regional para ser presentada ante el Segundo Congreso Mundial contra la explotación sexual comercial de niños, niñas y adolescentes que se realizaría en Yokohama (Japón). Los resultados de esta consulta regional quedaron plasmados en el documento "Compromiso para una estrategia contra la explotación sexual comercial y otras formas de violencia a la infancia y la adolescencia en la Región de América Latina y el Caribe" (IPEC/OIT, 2004a).

Como parte de los compromisos adquiridos en la reunión de Estocolmo, cinco años después, en el mes de diciembre de 2001, se realiza el Segundo Congreso Mundial contra la Explotación Sexual Comercial de personas menores de 18 años, en la ciudad de Yokohama. El compromiso adquirido en dicho congreso da especial importancia a la ratificación de los instrumentos internacionales en materia de protección a las personas menores de 18 
años, enfatizando la apremiante necesidad de impactar sobre los factores de vulnerabilidad que ponen en riesgo a los niños, niñas $y$ adolescentes frente al comercio sexual y sobre los factores de proclividad que promueven, toleran y legitiman la demanda de sexo con personas menores de 18 años.

Como resultado del congreso, se emite un "Compromiso Global" (el Compromiso Mundial de Yokohama), que reafirma y refuerza los acuerdos efectuados en el Primer Congreso Mundial de Estocolmo (1996) y en la Consulta Gubernamental Regional sobre Explotación Sexual Infantil efectuada en Montevideo (2001) (IPEC/OIT, 2004a).

Producto de estos dos congresos y con el propósito de dar continuidad a los compromisos adquiridos por los países en materia de prevención y eliminación de la explotación sexual comercial, distintas organizaciones conjugaron esfuerzos y realizaron en San José (Costa Rica) la Reunión de Seguimiento al Segundo Congreso Mundial de Yokohama (2004), con el objetivo de propiciar un espacio de reflexión, retroalimentación e intercambio regional en torno a los avances, obstáculos, retos $y$ lecciones aprendidas en materia de políticas públicas y planes de acción referentes a explotación sexual, haciendo énfasis en la prevención de los factores que originan la demanda $y$ los factores que ponen en riesgo a los niños, niñas y adolescentes frente a las redes de explotación (IPEC/OIT, 2004a).

Finalmente, del 25 al 28 de noviembre de 2008 , distintas organizaciones internacionales, representantes de gobiernos, organizaciones no gubernamentales, líderes religiosos, personas menores de edad, organismos de cooperación internacional, entre otras instancias, se reunieron en Río de Janeiro (Brasil) para efectuar el Tercer Congreso Mundial de Enfrentamiento a la Explotación Sexual de Niños y Adolescentes (Pacto de Río de Janeiro, noviembre de 2008).

En dicha actividad se lograron examinar los progresos $y$ acciones tomadas en seguimiento a la Declaración y Agenda para la Acción de Estocolmo (1996) y el Compromiso Global adquirido en Yokohama (2001). Asimismo, se identificaron diversas lecciones aprendidas e importantes desafíos que deben ser asumidos para prevenir, enfrentar y eliminar la explotación sexual de niños, niñas y adolescentes.

Algunos de estos retos apuntan a la inexistencia (en varios países) de leyes claras y eficaces que se dirijan a prevenir, atender o sancionar la Esc, dificultad que se acrecienta al no existir "datos confiables $y$ desagregados sobre la prevalencia y la naturaleza de [esta manifestación de violencia]" (Pacto de Río de Janeiro, noviembre de 2008 , p. 4).

La importancia de las señaladas reuniones internacionales radica en que los países participantes (entre ellos, Costa Rica) han vislumbrado la necesidad de elaborar planes nacionales de acción específicos para la prevención y la erradicación de la explotación sexual comercial, han constituido grupos de trabajo en contra de la temática, se han comprometido en la ratificación de los instrumentos internacionales en materia de protección a las víctimas $y$ han coincidido en la necesidad de propiciar espacios de reflexión nacional e internacional. En este sentido, de acuerdo con el Consejo Nacional de la Niñez y Adolescencia (2017), "Costa Rica ha desarrollado en las últimas décadas un Plan Marco de Acción (1998), un Plan de Intervención Inmediata (2000) y cuatro Planes Nacionales contra la explotación sexual comercial (2001, 2003-2006, 2008-2010 y 2017-2018)" (p. 6), por lo cual, esta instancia ya posee experiencia en esta materia; no obstante, la introducción de las nuevas tecnologías de la información y la comunicación han modificado las modalidades y manifestaciones de la Esc, $y$ han diversificado las formas de contacto y pago, lo que ha hecho que la detección y el abordaje de esta problemática se torne aún más difícil.

Si bien, la normativa internacional y las distintas reuniones políticas relacionadas al tema de ESC han evidenciado progresos en el abordaje y la sanción de este delito, también develan obstáculos que aún persisten en varios países de la región para lograr la desaparición absoluta de esta forma de esclavitud moderna. Algunos de estos vacíos pendientes son mencionados en la Declaración de Río de Janeiro (2008) y aluden a: 
La existencia significativa de lagunas en el conocimiento $y$ entendimiento de la forma de lidiar y responder a las manifestaciones emergentes, tendencias y complejidad de las diferentes formas de explotación sexual de niños, niñas y adolescentes.

La ausencia en muchos Estados, de leyes que definan y criminalicen adecuadamente las diferentes formas de explotación sexual, de acuerdo con los mínimos internacionales establecidos.

El aumento y persistencia de la impunidad.

La falta de investigación y de jurisdicción extraterritorial (acuerdos de extradición y repatriación) que faciliten la sanción de este delito.
La violación al derecho a la participación de las personas menores de edad en la implementación de políticas públicas que les conciernen.

La ausencia de recursos suficientes dedicados a la investigación de los delitos asociados al comercio sexual (Pacto de Río de Janeiro, noviembre de 2008).

\section{LEYES COSTARRICENSES EN MATERIA DE EXPLOTACIÓN SEXUAL COMERCIAL DE PERSONAS MENORES DE EDAD}

Luego de haber realizado un breve recorrido por la normativa $y$ las reuniones internacionales vinculadas al tema de ESC, resulta oportuno analizar los procesos de apropiación y armonización realizados por Costa Rica, en relación con la adscripción a dichas normas (figura 3).

FIGURA 3

INSTRUMENTOS NACIONALES EN MATERIA DE ESC
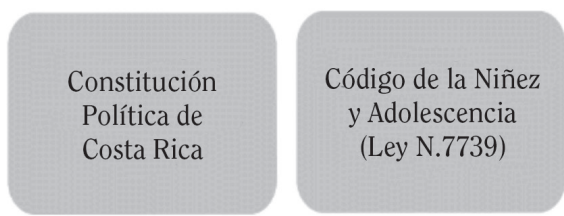

Ley contra la

Explotación Sexual

de las Personas

Menores de Edad

(Ley N.7899)

\section{Ley de}

Fortalecimiento de

la lucha contra la

ESC (Ley N.8590)
Ley contra la Trata de Personas (Ley N.9095)
Ley de Relaciones Impropias (Ley N.9406)
Ley Derecho al Tiempo (Ley N.7594)

Fuente: Elaboración propia.

Una de las primeras acciones realizadas por nuestro país luego de su participación en el Primer Congreso Mundial de Estocolmo (1996), fue el análisis y la revisión crítica de su normativa interna con el objetivo de poder identificar las principales reformas legislativas necesarias para proteger a las personas menores de edad del comercio sexual. Así, se reseña que: en la revisión y reforma de la legislación dirigida a sancionar esta grave violación de derechos humanos, participaron organizaciones privadas e instituciones públicas que han trabajado en la defensa de los derechos de la niñez y la adolescencia, esfuerzo 
que inicia en 1996 y culmina con la entrada en vigencia en 1999 de la Ley contra la Explotación Sexual de las Personas Menores de Edad (ley 7899) (IPEC/OIT, 2002, p. 43).

Algunos de los aportes más significativos que representaron la aprobación de esta ley son (IPEC/OIT, 2002):

$\diamond \quad$ Fue la primera ley en su tipo en toda América Latina.

$\diamond \quad$ Se re conceptualizó y amplió el delito de violación sexual (se incluye la violación con objetos $y$ dedos).

$\diamond \quad$ Se erradicaron los términos que revictimizaban y cuestionaban la "honestidad" de las víctimas, tales como estupro y abusos deshonestos.

$\diamond \quad$ La revictimización es el proceso mediante el cual se da una actualización de la victimización sufrida por una persona, a tal punto que se configura una nueva experiencia traumática para ella. Puede ser efectuada por la familia, las comunidades, las personas proveedoras de servicios o la sociedad en general, cuando se culpabiliza a una víctima por las consecuencias sufridas producto de la violación a alguno de sus derechos fundamentales. La revictimización que experimentan las personas menores de 18 años víctimas de explotación sexual comercial, violenta nuevamente su derecho a poseer una vida digna, libre de todo tipo de abuso y violencia (Claramunt, 2004a y 2004b).

$\diamond \quad$ Se crea el delito de relaciones sexuales remuneradas, el cual consiste en ofrecer $y$ brindar dinero o un supuesto beneficio a personas menores de 18 años para mantener relaciones sexuales con ellas $o$ para realizar otras actividades de carácter erótico.

$\diamond \quad$ Se crea el delito de fabricación, producción y difusión de pornografía.
Además, como resultado de los avances alcanzados con dicha ley, se instituye en el año 1999, la Comisión Nacional contra la Explotación Sexual Comercial de Personas Menores de Edad (CONACOES), la cual tiene como misión propiciar y fortalecer la coordinación y articulación interinstitucional, intersectorial e interdisciplinaria para afrontar integralmente la problemática de la ESC de personas menores de edad. A su vez, la conacoes es una Comisión Especial de Trabajo del Consejo Nacional de la Niñez y la Adolescencia (IPEC/oIT, 2002).

Más allá de que la Ley contra la ESc fue el primer referente costarricense $y$ latinoamericano en materia de sanción a este delito, también existen otras normativas internas que complementan y sirven de sustento a la aplicación efectiva de dicho instrumento legal. Es así que el marco jurídico nacional referente al tema de Esc debe incluir, además de la Ley 7899 (Asamblea Legislativa de Costa Rica, 1999), las siguientes normas:

$\diamond \quad$ La Constitución Política de Costa Rica (Asamblea Legislativa de Costa Rica, 1949) que, si bien no es una normativa específica en el tema de ESC, es la norma de superior rango en el ordenamiento jurídico del país (IPEC/OIT, 2002).

$\diamond \quad$ El Código de la Niñez y Adolescencia, Ley 7739 (Asamblea Legislativa de Costa Rica, 1998), el cual:

... da lugar a la creación del Sistema Nacional de Protección constituido por el Consejo Nacional de la Niñez y la Adolescencia (CNNA), las Juntas de Protección de la Niñez y la Adolescencia y los Comités Tutelares Comunitarios. Este código constituye [ ], por así decirlo, la principal ley que operacionaliza los postulados de la Convención [de Derechos del Niño] (IPEC/OIT, 2002, p. 50).

A su vez, posee la característica de que no contempla normas de naturaleza penal, no crea delitos, sino sanciones de multa o incumplimiento 
de las obligaciones establecidas en su articulado, por lo que carece de disposiciones expresas en materia de explotación sexual; solamente impone la obligatoriedad de denunciar penalmente cualquier sospecha razonable de maltrato o abuso cometido contra un niño, niña o adolescente (IPEC/OIT, 2002).

$\diamond \quad$ La Ley 8590, Ley de fortalecimiento de la lucha contra la ESC (Asamblea Legislativa de Costa Rica, 2007), la cual mediante una reforma al Código Penal y al Código Procesal Penal logró tipificar la tenencia de pornografía infantil como un delito de acción pública, así como ampliar los plazos para la prescripción de los delitos sexuales cometidos contra personas menores de edad; estos delitos prescribirían 10 años después de que la persona menor de edad cumpliera los 18 años. Recientemente, se aprobó la Ley de derecho al tiempo, Ley 7594 (Asamblea Legislativa de Costa Rica, 2019), en la cual se reforma de manera específica el artículo 31 del Código Procesal Penal, ampliando las garantías y la protección de las personas menores de edad víctimas de delitos sexuales, al extender el plazo de prescripción de estos crímenes de 10 a 25 años, lo cual permite que los niños, niñas $y$ personas adolescentes puedan denunciar hasta cumplir los 43 años.

$\diamond \quad$ La Ley 9095 vigente a partir del 8 de febrero de 2013, Ley contra la trata de personas y creación de la Coalición Nacional Contra el Tráfico Ilícito de Migrantes y la Trata de Personas (CONATT) (Asamblea Legislativa de Costa Rica, 2013), es relevante no solo por brindar un marco específico de acción en torno al tema de trata de personas, sino también por impulsar las sinergias y lazos de cooperación en la creación de la CONATT. de género asociadas a relaciones abusivas, reforma Código Penal, Código de Familia, Ley Orgánica TSE y Registro Civil y Código Civil", conocida como la Ley de Relaciones Impropias (Asamblea Legislativa de Costa Rica, 2017), en la cual se fortalece la protección de las personas menores de edad al penalizar las relaciones sexuales con personas menores de 18 años, cuando media en el vínculo una diferencia etaria suficiente (5 o 7 años) para establecer relaciones de poder a causa de la edad y prohibiendo el matrimonio de las personas menores de 18 años, lo que antes se conocía popularmente como "matrimonios tempranos".

Como puede observarse, la normativa costarricense relacionada con el tema de ESC, está dirigida no solamente a sancionar a quienes explotan sexualmente, sino también a crear mecanismos de protección y exigibilidad de derechos para todas las personas menores de 18 años; es así que gracias al reconocimiento de estas normas y de los principios que implican (principios de igualdad $y$ de no discriminación e interés superior del niño), es posible identificar dentro del derecho nacional una serie de garantías conculcadas, al presentarse un caso de explotación sexual comercial. Justamente, dichas garantías han sido reseñadas en el Código de Niñez y Adolescencia (CNA) con base en la Convención de los Derechos del Niño (CDN), como marco normativo internacional de referencia en el tema de políticas sociales dirigidas a las personas menores de edad.

Ahora bien, la armonización con las convenciones internacionales y el avance dentro de la normativa costarricense para prevenir, atender y sancionar la ESC ha sido notorio; sin embargo, aún se vislumbran varios obstáculos que deben ser superados para lograr una adecuada implementación de las políticas públicas dirigidas a la protección oportuna de las personas menores de edad víctimas de este delito y sobre todo, al fortalecimiento de sus familias frente al comercio sexual. 
DELIMITANDO RETOS Y ACCIONES PENDIENTES: IDENTIFICAR, ANALIZAR Y ACTUAR

Posterior al recorrido efectuado respecto a la normativa internacional $y$ nacional referente al tema del comercio sexual con personas menores de edad, es oportuno desarrollar algunas reflexiones acerca de su implementación e impacto.

Con el fin de desarrollar dicho ejercicio, es importante reconocer de manera inicial la relevancia que poseen las leyes en el accionar de las instituciones gubernamentales, ya que gracias a estas se pueden exigir normas mínimas en el abordaje de determinadas problemáticas sociales. En este sentido, las leyes - entendidas como una parte fundamental de las políticas públicas - pueden contribuir a disuadir y mitigar las consecuencias de la ESC, al instaurar sanciones contra quienes participen en las redes de explotación, a la vez que definen medidas de reparación y protección para las víctimas.

Es así como en Costa Rica se ha acuñado una legislación básica que busca prevenir y sancionar la ESC, acorde con la normativa y los principios internacionales. Este compromiso nacional resulta clave en la erradicación progresiva del comercio sexual, ya que evidencia la postura firme de las autoridades gubernamentales en establecer, implementar y vigilar la aplicación de las políticas y leyes, traduciendo a la acción interna los compromisos internacionales adquiridos (IPEC/OIT, 2004c; 2004d y 2004 e). No obstante, su aplicación también requiere la participación de diversos actores de la sociedad civil para lograr ser más efectiva, como por ejemplo: el sector turismo, el sector transporte (taxistas), las comunidades, entre otros. La inclusión activa de estos sectores es fundamental para la aplicación óptima de la normativa referida a la explotación sexual comercial de personas menores de edad.

De acuerdo con el más reciente informe de indicadores del Poder Judicial publicado en su página web, el cual data del año 2017 (Ministerio de Justicia y Paz, 2018; Observatorio de Violencia de Género contra las Mujeres y Acceso a la Justicia, 2019); se puede observar una importante diferencia entre las denuncias realizadas y el número de personas condenadas por delitos asociados a ESC (tabla 1 y 2). Por otra parte, la tabla 3 muestra la cantidad de víctimas por sexo para los delitos asociados a Esc en el año el 2017.

TABLA 1

DENUNCIAS NETAS POR DELITOS ASOCIADOS A ESC INTERPUESTAS ANTE EL MINISTERIO PÚBLICO Y EL ORGANISMO DE INVESTIGACIÓN JUDICIAL

\begin{tabular}{|c|c|c|c|}
\hline \multirow{2}{*}{ DELITO } & \multicolumn{3}{|c|}{ PERÍODO } \\
\hline & 2015 & 2016 & 2017 \\
\hline Actos sexuales remunerados con personas menores de edad & 38 & 24 & 43 \\
\hline Corrupción de menores agravada & 46 & 7 & 4 \\
\hline Corrupción de una persona menor de edad e incapaz & 47 & 65 & 103 \\
\hline Difusión de pornografía & 247 & 262 & 290 \\
\hline Fabricación, producción o reproducción de pornografía & 16 & 16 & 22 \\
\hline Relaciones sexuales con menores (tentativa de) & 294 & 254 & 59 \\
\hline Relaciones sexuales con personas menores de edad & 955 & 1096 & 2250 \\
\hline Relaciones sexuales remuneradas con menores de edad & 1 & 1 & 3 \\
\hline Relaciones sexuales remuneradas con personas menores de edad (tentativa de) & 0 & 0 & 2 \\
\hline Seducción o encuentros con menores por medios electrónicos & 82 & 96 & 186 \\
\hline Trata de personas & 55 & 96 & 145 \\
\hline TOTAL & 1781 & 1917 & 3107 \\
\hline
\end{tabular}

Fuente: Observatorio de Violencia de Género contra las Mujeres y Acceso a la Justicia, 2019. 
TABLA 2

PERSONAS CONDENADAS POR DELITOS ASOCIADOS A ESC

2017

\begin{tabular}{|c|c|c|c|}
\hline \multirow{2}{*}{ DELITO } & \multicolumn{2}{|c|}{ SEXO } & \multirow{2}{*}{ TOTAL } \\
\hline & MASCULINO & FEMENINO & \\
\hline Actos sexuales remunerados con personas menores de edad & 7 & 0 & 7 \\
\hline Corrupción de menores & 3 & 0 & 3 \\
\hline Difusión de pornografía & 4 & 0 & 4 \\
\hline Fabricación, producción o reproducción de pornografía & 1 & 0 & 1 \\
\hline Relaciones sexuales con menores de edad & 22 & 1 & 23 \\
\hline Relaciones sexuales remuneradas con menor o incapaz (tentativa de) & 1 & 0 & 1 \\
\hline Seducción o encuentros con menores por medios electrónicos & 4 & 0 & 4 \\
\hline Seducción o encuentros con personas menores de edad & 2 & 0 & 2 \\
\hline Trata de personas & 13 & 6 & 19 \\
\hline TOTAL & 57 & 7 & 64 \\
\hline
\end{tabular}

Fuente: Ministerio de Justicia y Paz, 2018 y Observatorio de Violencia de Género contra las Mujeres y Acceso a la Justicia, 2019.

TABLA 3

CANTIDAD DE VÍCTIMAS POR SEXO PARA LOS DELITOS ASOCIADOS A ESC DE ACUERDO CON EL MINISTERIO PÚBLICO, 2017

\begin{tabular}{|c|c|c|c|}
\hline \multirow{2}{*}{ DELITO } & \multicolumn{2}{|c|}{ VÍCTIMA } & \multirow{2}{*}{ TOTAL } \\
\hline & HOMBRE & MUJER & \\
\hline Actos sexuales remunerados con personas menores de edad & 9 & 28 & 37 \\
\hline Corrupción de una persona menor de edad e incapaz & 0 & 2 & 2 \\
\hline Fabricación, producción o reproducción de pornografía & 3 & 13 & 16 \\
\hline Relaciones sexuales con menores (tentativa de) & 1 & 1 & 2 \\
\hline Seducción o encuentros con menores por medios electrónicos & 25 & 139 & 164 \\
\hline Relaciones sexuales con menores de edad & 132 & 1930 & 2062 \\
\hline Relaciones sexuales remuneradas con menores & 2 & 8 & 10 \\
\hline TOTAL & 172 & 2121 & 2293 \\
\hline
\end{tabular}

Fuente: Ministerio de Justicia y Paz, 2018 y Observatorio de Violencia de Género contra las Mujeres y Acceso a la Justicia, 2019.

Como se mencionó anteriormente, el último año de actualización de los indicadores del Poder Judicial es el 2017 y desde entonces no es posible identificar en su página web datos comparativos similares recientes; por lo tanto, aunque esta información contribuye a clarificar el panorama respecto a las condenas para el caso de delitos vinculados con la ESC, resulta incompleta e insuficiente.

En este sentido, es posible percibir una respuesta institucional reducida a partir de la fase de detección, esto es, las estadísticas muestran cómo del número de casos detectados o denunciados, solo un reducido porcentaje de 
víctimas recibe atención y seguimiento, con el agravante de que un menor porcentaje alcanza la completa restitución de sus derechos y solo un escaso número de las personas adultas implicadas en los delitos, son capturadas y condenadas. Asimismo, es posible observar cómo la condición de género femenina constituye un factor de riesgo primordial para que una persona sea atrapada por las redes de explotación sexual comercial.

Si bien, estas estadísticas contribuyen a visualizar algunos de los retos que se deben asumir en relación con este tema, deben ser analizadas con cautela dado el carácter clandestino y el sub registro que existe en torno a los delitos asociados a esta violación de los derechos humanos de las personas menores de edad.

Ahora bien, con el objetivo de focalizar los desafíos pendientes que el Estado costarricense debe asumir para erradicar el comercio sexual de personas menores de edad, a continuación se especifican los principales obstáculos que han identificado tanto organizaciones estatales como organismos no gubernamentales e internacionales (IPEC/OIT, 2005b; Claramunt, 2008; Calderón y Salas, 2009; Castillo y Chinchilla, 2011; ECPAT Internacional, 2014; Consejo Nacional de la Niñez y la Adolescencia, 2017; Castillo, 2019), en la implementación eficaz y oportuna de la normativa vinculada al tema de ESc, los cuales pueden abreviarse de la siguiente manera:

$\diamond \quad$ Falta de protección efectiva $y$ desconocimiento de la aplicación de la normativa vigente por parte de las instituciones, al utilizar mecanismos y prácticas sustentadas en el enfoque de la situación irregular. La doctrina de la situación irregular se basa en el llamado enfoque de necesidades, modelo de atención que vela por la satisfacción de las necesidades de los niños, niñas $y$ adolescentes, $y$ no por el ejercicio de sus derechos humanos, además considera que las únicas personas menores de edad por las cuales debería preocuparse el Estado, son aquellas en las cuales su familia no cumple con su función protectora debido a alguna "irregularidad" o "disfuncionalidad" particular (Castillo y Chinchilla, 2011).

$\diamond \quad$ Costa Rica no cuenta con un sistema epidemiológico de registro $y$ vigilancia de la ESC - como expresión de la violencia interpersonal-; en contraste, solo es posible identificar iniciativas desagregadas $-y$ muchas veces poco documentadas o confusasque dan cuenta de la magnitud del problema desde los datos recabados en torno a las víctimas y desde la información recopilada respecto a los victimarios. En consecuencia, no es posible referir una valoración real de la magnitud del problema en el país (Castillo, 2019).

$\diamond \quad$ Ausencia de diagnósticos comunitarios que brinden una idea de los recursos de apoyo con los que se cuenta en las zonas en las cuales se implementan programas de atención o se han detectado mayor presencia de víctimas.

$\diamond \quad$ Desconocimiento de las diferentes dinámicas de la EsC por parte de instituciones clave en su abordaje, lo cual origina poca aplicación de la ley.

$\diamond \quad$ El uso de tecnologías de la información y comunicación (TICS) y redes sociales, han originado nuevas formas de captación y de vulnerabilidad para las personas menores de edad; en este sentido, también existe un vacío en la legislación nacional para hacer frente a estas nuevas modalidades de la ESC que son facilitadas por la tecnología, algunas de estas son el sexting, el grooming y el morphing. El sexting alude al envío de mensajes de texto, imágenes o vídeos de carácter sexual o erótico; el grooming o seducción en línea, es la búsqueda con fines sexuales de personas menores de edad por medio 
de las tecnologías, y el morphing, es entendido como un mecanismo digital para manipular imágenes de niños, niñas $y$ adolescentes con el objetivo de mostrarles en actividades sexuales 0 eróticas (ECPAT Internacional, 2014).

Debilidad en los procesos de denuncia, debido al temor, al desconocimiento de la ley y a la tolerancia de las comunidades ante el abuso, la explotación y el maltrato.

Falta de capacitación a funcionarios $y$ funcionarias de las instituciones gubernamentales, que facilite la aplicación de la normativa en torno a la ESC. Al respecto, gran cantidad de proveedores y proveedoras de servicios aún carecen de conocimientos alusivos al enfoque de derechos humanos y a la doctrina de protección integral por lo que deben ser capacitados perentoriamente, dichos procesos de adiestramiento deben incidir no solo en la esfera de los conocimientos, sino también en las actitudes y prácticas efectuadas por las personas funcionarias. Capacitar brindando solamente información, sin buscar impactar en las actitudes y prácticas ha demostrado ser insuficiente en la lucha contra la ESC y en la aplicación de la normativa vigente (Castillo y Chinchilla, 2011).

$\diamond \quad$ Falta de indicadores de éxito para medir el impacto de las acciones institucionales.

$\diamond \quad$ Poca efectividad de las respuestas institucionales, ya que - en muchas ocasiones - dependen de la voluntad de las funcionarias y los funcionarios.

$\diamond \quad$ Desarticulación constante de la plataforma de servicios institucionales, necesaria para desarrollar acciones frente al comercio sexual.
Todos estos obstáculos en la aplicación de la normativa en torno a la ESC pueden explicarse desde diversos puntos de partida; sin embargo, una de las aristas que más sobresale es la tolerancia social en el ámbito local y la permanencia del enfoque de la situación irregular en el accionar de las proveedoras y los proveedores de servicios, quienes por mandato gubernamental deben tutelar los derechos de las personas menores de edad. Así, la solución a esta incompatibilidad entre lo que sustenta la norma y lo que se realiza en la práctica o lo que se vive en las comunidades, puede ser soslayada por medio del fomento de políticas culturales que acompañen y complementen a las leyes. Otras recomendaciones que podrían ejecutarse para resolver tal discrepancia son:

$\diamond \quad$ Crear planes de atención a las víctimas y a sus familias sustentados en el modelo cíclico de respuestas articuladas (Claramunt, 2005a y 2005b), ya que este modelo ha mostrado una alta efectividad en la protección de muchos niños, niñas $y$ adolescentes. Dicho modelo brinda una respuesta cíclica al fenómeno de la ESC, en contraposición a las respuestas lineales que han caracterizado tradicionalmente a los modelos de atención (Castillo y Chinchilla, 2011).

$\diamond \quad$ Crear $y$ homologar protocolos e instrumentos de detección en las instituciones, para evitar la duplicidad de documentos $y$ así facilitar el cumplimiento de los mandatos gubernamentales.

$\diamond \quad$ Sensibilizar y capacitar al personal de las instituciones estatales. Dichos procesos de capacitación y sensibilización deben incorporar el abordaje de las actitudes que poseen las proveedoras y los proveedores de servicios en torno a la ESc, la pobreza, la diversidad sexual y la sexualidad en general. Al respecto, se ha advertido que el incumplimiento de muchas políticas públicas se basa en el impacto 
que poseen las actitudes sexistas, androcentristas y no sensibles al género en las prácticas institucionales (Fallas y Morera, 2004).

Consolidar los procesos de denuncia e investigación criminal, por medio de la capacitación al sector represivo y al sector judicial.

Incorporar agentes "no tradicionales" en los procesos de detección y atención a víctimas de explotación sexual comercial; perfilándose en este ámbito un papel clave de las comunidades directa e indirectamente implicadas en redes de Esc, así como de organizaciones de la sociedad civil.

La articulación y coordinación interinstitucional, intersectorial $y$ con los subsistemas locales de protección, permite que las acciones que se realicen en torno al trabajo de combate contra la Esc, sean eficientes, eficaces, $y$ permitan un mejor aprovechamiento de uso de los recursos (Consejo Nacional de la Niñez y la Adolescencia, 2017, p.10).

$\diamond \quad$ Buscar la creación de programas de seguimiento que fortalezcan las redes de apoyo locales.

$\diamond \quad$ Institucionalizar mecanismos de auto cuidado para los funcionarios $y$ las funcionarias como un factor protector con miras a obtener un mejor desempeño en sus labores que contribuya a su vez a mejorar la aplicación de la normativa en torno al tema.

\section{REFLEXIONES FINALES}

El recorrido efectuado con anterioridad vislumbra cómo el Estado costarricense debe conjugar nuevos esfuerzos para que la aplicación de la normativa nacional e internacional en relación con el comercio sexual con personas menores de edad sea más efectiva. Asimismo, debe promover dentro de las comunidades $y$ dentro de todas sus instituciones, una cultura de cero tolerancia hacia este delito y desarrollar sinergias que busquen impactar tanto en su génesis, como en su evolución, silenciamiento y legitimación social. Otras necesidades inmediatas que deben ser asumidas, incluyen el trabajar con el potencial contenedor de las familias $y$ fortalecer la respuesta ante el problema en el nivel local, es decir, dentro de las comunidades, ya que la respuesta a esta problemática no puede darse de forma aislada sin la presencia o inclusión ciudadana, pues es justamente por la permisividad existente en las comunidades y por la falta de impacto a nivel local que los factores de riesgo frente a la ESC se mantienen a pesar de la normativa existente.

El fenómeno de la explotación sexual comercial exige que las instituciones del Estado cumplan con sus obligaciones, asuman los retos pendientes y brinden protección $y$ seguridad a todas las personas menores de edad, dando así sentido real al principio rector del interés superior, consagrado en la Convención de los Derechos del Niño; para ello, el trabajo en el desarrollo de políticas culturales es fundamental para cambiar dentro de las familias y las comunidades más vulnerabilizadas socialmente, la visión que se tiene en torno al comercio sexual con personas menores de 18 años.

Solamente el trabajo en conjunto con $y$ para las comunidades, efectuado de forma articulada, podrá dar respuesta a las múltiples necesidades de las víctimas y de sus familias. Del mismo modo, solo fortaleciendo los esfuerzos a nivel local, nacional, regional, sub regional e internacional se logrará prevenir y erradicar la explotación sexual comercial de personas menores de edad, propiciando un ambiente de seguridad que brinde bienestar real, en el cual se respeten sus garantías fundamentales y se les aleje de cualquier manifestación de la violencia social o familiar.

Sin este trabajo conjunto y sin la revisión de nuestras actitudes personales frente al comercio sexual, no existirá normativa nacional o internacional que asegure la dignidad e integridad de las personas menores de edad frente a 
estas redes de delincuencia organizada, ya que quienes promueven la explotación sexual siempre buscarán un portillo para captar y violentar a aquellos niños, niñas $y$ adolescentes que identifiquen como vulnerables, haciendo cumplir el viejo refrán: "hecha la ley, hecha la trampa".

\section{REFERENCIAS}

Asamblea General de las Naciones Unidas. (1989). Convención sobre los Derechos del Niño, Resolución 44-25-1989. onU, Nueva York, Estados Unidos.

Asamblea General de las Naciones Unidas. (2000a). Convención de las Naciones Unidas contra la Delincuencia Organizada Transnacional. Nueva York, Estados Unidos.

Asamblea General de las Naciones Unidas. (2000b). Protocolo facultativo relativo a la venta de infantes, la prostitución de menores y la pornografía infantil, Resolución A/RES/54/263-2000. ONU.

Asamblea General de las Naciones Unidas. (2000c). Protocolo para prevenir, reprimir y sancionar la trata de personas, especialmente mujeres y niños, que complementa la Convención de las Naciones Unidas contra la Delincuencia Organizada Transnacional (Protocolo de Palermo). ONU.

Asamblea Legislativa de Costa Rica. (1949). Constitución Política de la República de Costa Rica. Edición actualizada, 2015. San José, Costa Rica.

Asamblea Legislativa de Costa Rica. (1998). Ley Código de la Niñez y la Adolescencia nro.7739. Diario Oficial La Gaceta 26. San José, Costa Rica.

Asamblea Legislativa de Costa Rica. (1999). Ley Contra la Explotación Sexual de las Personas Menores de Edad nro. 7899. Diario Oficial La Gaceta 159. San José, Costa Rica.

Asamblea Legislativa de Costa Rica. (2007). Ley Fortalecimiento de la Lucha contra la Explotación Sexual de las Personas Menores de Edad nro. 8590. Diario Oficial La Gaceta 166. San José, Costa Rica.
Asamblea Legislativa de Costa Rica. (2013). Ley Contra la Trata de Personas y creación de la Coalición contra el Tráfico Ilícito de Migrantes y la Trata de Personas (CONATT) nro. 9095. Diario Oficial La Gaceta 28. San José, Costa Rica.

Asamblea Legislativa de Costa Rica. (2017). Ley Fortalecimiento de la protección legal de las niñas y las adolescentes mujeres ante situaciones de violencia de género asociadas a relaciones abusivas, reforma Código Penal, Código de Familia, Ley Orgánica TSE y Registro Civil y Código Civil nro. 9406. Diario Oficial La Gaceta 10. San José, Costa Rica.

Asamblea Legislativa de Costa Rica. (2019). Ley Derecho al Tiempo. Reforma del artículo 31 del Código Procesal Penal nro. 7594. Diario Oficial La Gaceta 51. San José, Costa Rica.

Bruna, N. (2003). Estudio sobre la situación de la explotación sexual comercial de las personas menores de edad en San José y Ciudad Quesadal Diagnóstico realizado por el Equipo Profesional del Proyecto Semillas de Esperanza. D.N.I.

Calderón, A. y Salas, J. (2009). El comercio sexual con personas menores de edad en Centroamérica, Panamá y República Dominicana: segundo estudio de tolerancia social. Análisis de resultados, desafíos y recomendaciones. OIT/IPEC.

Castillo, A. (2019). Más allá de los "datos": una breve reflexión desde la epidemiología social a los sistemas tradicionales de información y vigilancia de la violencia. Revista de Ciencias Sociales, (163), 89-99.

Castillo, A. y Chinchilla, I. (2011). La experiencia de la Escuela de Psicología de la Universidad de Costa Rica en la atención de la explotación sexual comercial: un acercamiento crítico al modelo cíclico de respuestas articuladas como estrategia para garantizar la protección integral de derechos. Revista Latinoamericana de Derechos Humanos, (24), 121-151.

Claramunt, C. (2004a). Propuesta de atención a Víctimas. Proyecto Contribuyendo a 
la erradicación de la explotación sexual comercial de niños, niñas y adolescentes. Escuela de Psicología/Universidad de Costa Rica-OIT/IPEC.

Claramunt, C. (2004b). Violencia basada en género $y$ derechos humanos: aproximaciones para trascender el enfoque psicologista de los programas de atención a las víctimas. La violencia contra la mujer: Un problema de Salud Pública y una violación a los Derechos Humanos. Pro familia.

Claramunt, C. (2005a). ¿Qué puedo hacer para combatir la explotación sexual comercial? OIT/IPEC.

Claramunt, C. (2005b). El Modelo Cíclico de Respuestas Articuladas como estrategia para garantizar la protección integral de derechos. Explotación sexual comercial. Propuestas de trabajo para una atención integral a las personas menores de edad víctimas. OIT/IPEC.

Claramunt, C. (2008). El quehacer de la Escuela de Psicología frente al comercio sexual de niñas, niños y personas adolescentes. Escuela de Psicología, Universidad de Costa Rica.

Consejo Nacional de la Niñez y la Adolescencia. (2017). Plan Nacional de Acción contra la Explotación Sexual Comercial 20172018. Patronato Nacional de la Infancia.

ECPAT Internacional. (2014). Informe de monitoreo de país sobre la explotación sexual comercial de niños, niñas y adolescentes (ESCNNA): Costa Rica. Fundación Paniamor y ECPAT Internacional.

Fallas, G. y Morera, G. (2004). Explotación Sexual Comercial de Niños, Niñas y Adolescentes: conocimientos, actitudes y prácticas de proveedores de servicios públicos de salud (CCSS) de la Provincia de Limón [Tesis para optar por el grado de Licenciatura en Psicología]. Universidad de Costa Rica.

Marshall, T. y Bottomore, T. (1998). Ciudadanía y clase social. Alianza.

Ministerio de Justicia y Paz. (2018). Anuario estadístico del año 2017.

Monge, I. y Cruz, F. (2004). Explotación sexual comercial, Contenidos mínimos en materia de penalización de la explotación sexual comercial de personas menores de 18 años, según las normas internaciones. OIT/IPEC.

Naciones Unidas. (2018). Agenda 2030 y los Objetivos de Desarrollo Sostenible: una oportunidad para América Latina y el Caribe. Comisión Económica para América Latina y el Caribe (Cepal)/ Naciones Unidas (NU).

Observatorio de Violencia de Género contra las Mujeres y Acceso a la Justicia. (2019). Delitos Sexuales. Poder Judicial. https:// observatoriodegenero.poder-judicial. go.cr/soy-especialista-busco/estadisticas/ delitos-sexuales/

Organización de los Estados Americanos [oeA]. (1994). Convención Interamericana sobre tráfico internacional de menores. Ciudad de México, México.

Organización de Naciones Unidas [onu]. (18 de diciembre de 1979). Convención sobre la eliminación de todas las formas de discriminación contra la mujer (CEDAW). Adoptada y abierta a la firma y ratificación, o adhesión, por la Asamblea General en su resolución 34/180.

Organización Internacional del Trabajo [OIT]. (1999a). Convenio 182 sobre la prohibición de las peores formas de trabajo infantil y la acción inmediata para su eliminación (C 182). Conferencia General de la Organización Internacional del Trabajo nro. 87. Ginebra, Confederación Suiza.

Organización Internacional del Trabajo [OIT]. (1999b). Recomendación sobre la prohibición de las peores formas de trabajo infantil y la acción inmediata para su eliminación ( $R$ 190). Ginebra, Confederación Suiza.

Pacto de Río de Janeiro. (noviembre de 2008). Declaración del tercer congreso mundial en contra de la ESC, celebrado en Brasil. Documento no publicado.

Programa Internacional para la Erradicación del Trabajo Infantil y Organización Internacional del Trabajo [IPEc/OIT]. (2002). Explotación sexual comercial en Costa Rica. 
Programa Internacional para la Erradicación del Trabajo Infantil y Organización Internacional del Trabajo [IPEC/OIT]. (2004a). Memoria de la Reunión de Seguimiento de II Congreso Mundial Contra la explotación sexual comercial de personas menores de 18 años. Que tu mirada siempre sea vigilante.

Programa Internacional para la Erradicación del Trabajo Infantil y Organización Internacional del Trabajo [IPEC/OIT]. (2004b). Ojos que sí ven, corazón que sí siente. Manual para profesoras y profesores dirigido a la prevención y eliminación de la explotación sexual comercial de personas menores de 18 años en Guatemala.

Programa Internacional para la Erradicación del Trabajo Infantil y Organización Internacional del Trabajo [IPEc/OIT]. (2004c). Trata con fines de explotación sexual comercial.

Programa Internacional para la Erradicación del Trabajo Infantil y Organización Internacional del Trabajo [IPEC/OIT]. (2004d). Diferencias entre el tráfico ilicito de migrantes y la trata de personas menores de edad.

Programa Internacional para la Erradicación del Trabajo Infantil y Organización Internacional del Trabajo [IPEc/oIT]. (2004e). Trabajo Infantil: un manual para estudiantes.

Programa Internacional para la Erradicación del Trabajo Infantil y Organización Internacional del Trabajo [IPEC/OIT], (2005a). Documento de información básica sobre explotación sexual comercial de personas menores de 18 años en Centroamérica, Panamá y República Dominicana: ¡Cada pieza cuenta!

Programa Internacional para la Erradicación del Trabajo Infantil y Organización Internacional del Trabajo [IPEc/oIT]. (2005b). Sistematización de la Reunión Técnica (SPIF) para recibir insumos para la formulación del componente de atención directa a víctimas de explotación sexual comercial de la Segunda Fase del Proyecto Subregional de contribución a la prevención y eliminación de la explotación sexual comercial de personas menores de edad en Centroamérica, Panamá y República Dominicana [manuscrito sin publicar].

Programa Internacional para la Erradicación del Trabajo Infantil y Organización Internacional del Trabajo [IPEC/OIT]. (2007). Compendio de legislación para penalizar la explotación sexual comercial de personas menores de edad en Centroamérica, Panamá y República Dominicana.

Salas, J. y Campos, Á. (2004). Explotación sexual comercial: un estudio regional cualitativo con hombres de la población general. OIT/IPEC.

Fecha de ingreso: $12 / 04 / 2019$ Fecha de aprobación: 15/10/2019 
